\title{
PERBEDAAN PENGARUH ANTARA KRISTALOID DAN KOLOID TERHADAP PERUBAHAN ELEKTROLIT (Na, K, Cl)
}

\author{
Maya Sapti Puspitosari ${ }^{1}$, Hari Wujoso ${ }^{1}$, Marthunus Judin ${ }^{1}$ \\ Program Studi Kedokteran Keluarga, Program Pascasarjana, Universitas Sebelas Maret \\ Surakarta.
}

\begin{abstract}
Abstrak. Cairan tubuh manusia sekitar 60\% dari berat badan (BB) tubuh yang terdiri dari elektrolit dan non elektrolit. Resusitasi cairan pada pasien operasi harus dimonitoring dengan baik untuk menghindari terjadinya gangguan keseimbangan asam basa tubuh. Pemberian cairan pada pasien yang akan operasi, khususnya section caesaria (SC). Monitoring elektrolit pasien yang menjalani operasi penting dilakukan. Penulis tertarik untuk melakukan penelitian mengenai pengaruh pemberian cairan kristaloid dan koloid sebagai cairan pengganti pasien yang menjalani operasi. Tujuan penelitian ini adalah menganalisis perbedaan pengaruh antara kristaloid dan koloid terhadap perubahan elektrolit $(\mathrm{Na}, \mathrm{K}, \mathrm{Cl})$ pasca operasi sectio caesaria. Penelitian dilakukan di Instalasi Bedah Pusat RSUD Dr. Moewardi Surakarta, dimulai pada bulan Juni sampai September 2015. Jenis penelitian eksperimental berupa uji klinik dengan desain single blind pre and post test accidental control trial pada pasien yang menjalani operasi sectio caesaria elektif dan emergensi sebagai subyek penelitian. Kelompok penelitian dibagi menjadi dua yaitu kelompok Kristaloid (K1), dan Koloid (K2). Terdapat perbedaan yang signifikan kadar elektrolit $(\mathrm{Na}, \mathrm{K}$, dan $\mathrm{Cl}$ ) sebelum dan sesudah perlakuan pada kelompok yang diberi cairan ringerfundin dimana terjadi penurunan kadar $\mathrm{Na}=2,0 \%, \mathrm{~K}=12,1 \%$, dan $\mathrm{Cl}=3,2 \%$. Ringerfundin dan tetraspan sama-sama dapat mencegah turunnya elektrolit pada pasien operasi $(\mathrm{p}>0,05)$. Pada kelompok ringerfundin terjadi penurunan/perubahan kadar elektrolit yang signifikan ( $<<0,05)$, sedangkan pada kelompok tetraspan kadar elektrolit tidak terjadi penurunan/perubahan signifikan $(p>0,05)$ sehingga dapat diketahui bahwa terdapat perbedaan pengaruh pemberian ringerfundin dan tetraspan terhadap perubahan kadar elektrolit.Kesimpulan pada penelitian ini adalah terdapat perbedaan pengaruh pemberian ringerfundin dan tetraspan terhadap perubahan kadar elektrolit dimana pemberian tetraspan sebagai cairan perioperatif dapat mempertahankan keseimbangan kadar elektrolit tubuh lebih baik daripada cairan ringerfundin
\end{abstract}

Kata kunci: Ringerfundin, Tetraspan, Kadar Elektrolit.

\begin{abstract}
.
Background:Human body fluids is about $60 \%$ of body weight (BW) consist of electrolyte and non-electrolytes compounds. Fluid resucitation in surgery patients must be monitored in order to avoid interference with the body's acidbase balance. Electrolyte levels before fluid administration in patients who will have surgery, especially Section Caesaria, are rarely meassured, which may cause electrolyte balance problems that will aggravate the metabolic process and its treatment. Electrolyte monitoring in undergoing surgery patients is necessary. It is closely related to fluid administration either pre,
\end{abstract}


peri, and post surgery. Authors interested in conducting research on the effect of crystalloid and colloid fluid as a replacement fluid in undergoing surgery patients. Objective: to analyze whether there were differences between crystalloid and colloid effects on electrolyte levels ( $\mathrm{Na}, \mathrm{K}, \mathrm{Cl}$ ) in post-operative SectioCaesaria patients. Method: A clinical trials with single-blind design and pre-and post-test accidental controlled trials was conducted at Surgery Center in Moewardi Hospital of Surakarta, starting from June to September 2015. Subjects were patients who were undergoing elective and emergency SectioCaesaria surgery. Subjects were divided into two groups; Crystalloids ( K1), and Colloid ( K2 ). Result: There were significant differences in levels of electrolytes ( $\mathrm{Na}, \mathrm{K}$, and $\mathrm{Cl}$ ) before and after treatment in the group given ringerfundin fluid, there were decreases in levels of $\mathrm{Na}=2.0 \%, \mathrm{~K}=12.1 \%$, and $\mathrm{Cl}=3.2 \%$. Both ringerfundin and tetraspan could prevent the decrease of electrolytes in surgery patients $(p>0.05)$. In the ringerfundin group decrease/changes in electrolyte levels were significant $(p<0.05)$, whereas in the tetraspan group the electrolyte levels did not decrease/change significantly $(p>0.05)$. Conclusion:There were differences in the effect of ringerfundin and tetraspan on electrolyte levels where tetraspan as perioperative fluid administration could maintain the body's electrolyte balance levels better than ringerfundin liquids.

Keywords: ringerfundin, tetraspan, electrolyte levels

PENDAHULUAN

Cairan tubuh manusia sebagian besar terdiri dari air. Sekitar $60 \%$ dari berat badan (BB) tubuh. Air dan zat-zat yang terlarut di dalamnya disebut dengan cairan tubuh yang terdiri dari elektrolit dan non elektrolit.

Terjadinya gangguan volume pada masing-masing kompartemen cairan tubuh sering berhubungan dengan gangguan pada keseimbangan elektrolit terutama Na. Mekanisme homeostatik tubuh secara neurohormonal akan mengatur keseimbangan ini sehingga gangguan tersebut harus diatasi dengan memberikan terapi yang sesuai dengan gangguan yang timbul (Ganong, 2005; Mulyono dan Sunatrio, 2009).
Resusitasi cairan pada pasien operasi harus dimonitoring dengan baik, bertujuan untuk menghindar terjadinya gangguan pada keseimbangan asam basa tubuh.

Pemberian cairan pada pasien yang akan operasi, khususnya section caesaria (SC), sebelumnya jarang dilakukan pemeriksaan elektrolit, sehingga dapat menimbulkan gangguan keseimbangan elektrolit yang akan memperberat proses metabolik dan penyembuhannya. Pemeriksaan elektrolit setelah operasi sangat penting, karena intervensi cairan selama operasi, dengan alasan untuk mengontrol elektrolit dan keseimbangan asam-basa (Rudi et. al., 2012).

Tabel 1. Distribusi Karakteristik Responden antar Kelompok Perlakuan

\begin{tabular}{llcccc}
\hline \multicolumn{1}{c}{ Karakteristik } & Kelompok & N & Mean & SD & p-value \\
\hline Umur* & Ringerfundin & 10 & 26.90 & 7.13 & 0.463 \\
(tahun) & Tetraspan & 10 & 29.10 & 5.93 & \\
Lama Operasi** & Ringerfundin & 10 & 66.50 & 17.00 & 0.165 \\
(Menit) & Tetraspan & 10 & 77.50 & 13.59 & \\
Pendaharahan** & Ringerfundin & 10 & 384.00 & 155.29 & 0.631 \\
(ml) & Tetraspan & 10 & 400.00 & 149.07 & \\
\hline
\end{tabular}


Dari ulasan diatas, dapat diketahui bahwa monitoring elektrolit pasien yang menjalani operasi penting dilakukan. Hal ini erat kaitannya dengan pemberian cairan baik pre, peri, dan juga post operatif. Sehingga penulis tertarik untuk melakukan penelitian mengenai pengaruh pemberian cairan kristaloid dan koloid sebagai cairan pengganti pasien yang menjalani operasi.

\section{METODE PENELITIAN}

Penelitian dilakukan di Instalasi Bedah Pusat RSUD Dr. Moewardi Surakarta, dimulai pada bulan Juni sampai September 2015. Jenis penelitian eksperimental berupa uji klinik dengan desain single blind pre and post test accidental control trial pada pasien yang menjalanai operasi sectio caesaria elektif dan emergensi sebagai subyek penelitian dengan tujuan mencari perbedaan efektivitas pemberian infus kristaloid dan koloid terhadap perubahan elektrolit Na, K, dab Cl. Kelompok penelitian dibagi menjadi dua yaitu kelompok Kristaloid (K1), dan Koloid (K2).

\section{HASIL DAN PEMBAHASAN}

Karakteristik responden antar kelompok perlakuan tidak berbeda signifikan $(\mathrm{p}>0,05)$, sehingga responden dalam penelitian ini baik digunakan dalam penelitian dapat dilihat dalam Tabel 1. Penelitian ini adalah menguji adakah perbedaan kadar elektrolit: Natrium $(\mathrm{Na})$, Kalium $(\mathrm{K})$, dan Chlorida $(\mathrm{Cl})$ antara kelompok yang diberi cairan ringerfundin dan tetraspan.

Tabel 2. Uji Normalitas Data Penelitian

\begin{tabular}{lllcc}
\hline Parameter & Kelompok & N & p-value & Normalitas \\
\hline Na Pretest & Ringerfundin & 10 & 0.088 & Normal \\
& Tetraspan & 10 & 0.102 & Normal \\
\hline \multirow{2}{*}{ K Pretest } & Ringerfundin & 10 & 0.067 & Normal \\
& Tetraspan & 10 & 0.818 & Normal \\
\hline \multirow{2}{*}{ Na Pretest } & Ringerfundin & 10 & 0.998 & Normal \\
& Tetraspan & 10 & 0.269 & Normal \\
\hline \multirow{2}{*}{ P Posttest } & Ringerfundin & 10 & 0.417 & Normal \\
& Tetraspan & 10 & 0.231 & Normal \\
\hline \multirow{2}{*}{ Cl Posttest } & Ringerfundin & 10 & 0.395 & Normal \\
& Tetraspan & 10 & 0.989 & Normal \\
\hline
\end{tabular}

Berdasarkan Tabel 1 diketahui bahwa nilai $\mathrm{p}$-value $>0,05$ pada setiap parameter penelitian baik data pretest (sebelum perlakuan) dan posttest (sesudah perlakuan). Sehingga dalam penelitian ini dalam menguji perbedaan kadar elektrolit: Natrium (Na), Kalium (K), dan Chlorida $(\mathrm{Cl})$ antara kelompok yang diberi cairan ringerfundin dan tetraspan dengan menggunakan uji independent sampel $t$ test dan untuk mengetahui perbedaan kadar elektrolit sebelum dan sesudah perlakuan pada setiap kelompok perlakuan menggunakan uji paired sampel t test.

Berdasarkan Tabel 3 diketahui bahwa kadar Natrium (Na) mendapatkan nilai p-value $0,949$ ( $p>0,05)$ yang berarti tidak tedapat perbedaan kadar natrium atara kelompok ringerfundin dan tetraspan sebelum diberi perlakuan. 
Tabel 3 Perbedaan Kadar Elektrolit (Na, K, Dan Cl) Sebelum Perlakuan antara kelompok Ringerfundin dan Testrapan

\begin{tabular}{cccc}
\hline $\begin{array}{c}\text { Kadar } \\
\text { Sebelum }\end{array}$ & Ringerfundin & Tetraspan & p-value \\
\hline $\mathrm{Na}$ & $139,70 \pm 3,37$ & $139,60 \pm 3,57$ & 0,949 \\
$\mathrm{~K}$ & $3,90 \pm 0,77$ & $4,06 \pm 0,70$ & 0,633 \\
$\mathrm{Cl}$ & $108,60 \pm 2,59$ & $108,20 \pm 1,93$ & 0,700 \\
\hline
\end{tabular}

Kadar Kalium (K) mendapatkan nilai p-value $0,633(p>0,05)$ yang berarti tidak terdapat perbedaan kadar kalium antara kelompok ringerfundin dan tetraspan sebelum diberi perlakuan. Kadar Chlorida (Cl) mendapatkan nilai $\mathrm{p}$-value $0,700(\mathrm{p}>0,05)$ yang berarti tidak terdapat perbedaan kadar Chlorida antara kelompok ringerfundin dan tetraspan sebelum diberi perlakuan.
Berdasarkan uraian diatas maka dapat diketahui bahwa tidak ada perbedaan kadar elektrolit $(\mathrm{Na}, \mathrm{K}$, dan $\mathrm{Cl}$ ) antara kelompok ringerfindin dan tetraspan sebelum adanya perlakuan. Sehingga dapat dikatakan bahwa antara kelompok ringerfundin dan tetraspan memiliki kadar elektrolit yang sama.

Tabel 4 Perbedaan Kadar Elektrolit (Na, K dan Cl) Sesudah Perlakuan antara Kelompok Ringerfundin dan Tetraspan.

\begin{tabular}{cccc}
\hline $\begin{array}{c}\text { Kadar } \\
\text { Sesudah }\end{array}$ & Ringerfundin & Tetraspan & p-value \\
\hline $\mathrm{Na}$ & $136,90+2,89$ & $138,70+3,30$ & 0,211 \\
$\mathrm{~K}$ & $3,43+0,74$ & $4,01+0,77$ & 0,103 \\
$\mathrm{Cl}$ & $105,10+3,90$ & $108,10+2,38$ & 0,052 \\
\hline
\end{tabular}

Berdasarkan Tabel 4 diketahui bahwa kadar Natrium (Na) mendapatkan nilai p-value 0,211 ( $>00,05)$ yang berarti kadar natrium antara kelompok ringerfundin dan tetraspan tidak berbeda signifikan setelah diberi perlakuan

Kadar Kalium (K) mendapatkan nilai p-value 0,103 $(\mathrm{p}>0,05)$ yang berarti kadar kalium antara kelompok ringerfundin dan tetraspan tidak berbeda signifikan setelah diberi perlakuan.
Kadar Chlorida $(\mathrm{Cl})$ mendapatkan nilai p-value 0,700 ( $>>0,05)$ yang berarti kadar Chlorida antara kelompok ringerfundin dan tetraspan tidak berbeda signifikan setelah diberi perlakuan..

Berdasarkan uraian diatas maka dapat diketahui bahwa tidak ada perbedaan kadar elektrolit $(\mathrm{Na}, \mathrm{K}$, dan $\mathrm{Cl})$ antara kelompok ringerfindin dan tetraspan setelah adanya perlakuan. Sehingga dapat dikatakan bahwa baik cairan ringerfundin dan tetraspan dapat sama-sama dapat menjaga elektrolit setelah adanya operasi.

Tabel 5 Perbedaan Kadar Elektrolit (Na, K, Dan Cl) Sebelum dan Sesudah Perlakuan Pada kelompok Ringerfundin

\begin{tabular}{cccc}
\hline Ringerfundin & Sebelum & Sesudah & p-value \\
\hline $\mathrm{Na}$ & $139,70+3,37$ & $136,90+2,89$ & 0,000 \\
$\mathrm{~K}$ & $3,90+0,77$ & $3,43+0,74$ & 0,008 \\
$\mathrm{Cl}$ & $108,60+2,59$ & $105,10+3,90$ & 0,002 \\
\hline
\end{tabular}


Kadar Natrium (Na) mendapatkan nilai $p$-value $0,000(\mathrm{p}<0,05)$ yang berarti kadar natrium antara sebelum dan sesudah perlakuan berbeda signifikan pada kelompok ringerfundin. Dimana pada kelompok ringerfundin didapatkan nilai selisih penurunan rata-rata kadar natrium sebesar 2,80, sehingga dapat diketahui adanya penurunan kadar natrium sebesar 2\% (2,80/139,70*100\%).

Kadar Kalium (K) mendapatkan nilai $p$-value $0,008(\mathrm{p}<0,05)$ yang berarti kadar Kalium antara sebelum dan sesudah perlakuan berbeda signifikan pada kelompok ringerfundin. Dimana pada kelompok ringerfundin didapatkan nilai selisih penurunan rata-rata kadar Kalium sebesar 0,47, sehingga dapat diketahui adanya penurunan kadar Kalium sebesar 12,05\% (0,47/3,90*100\%).

Kadar Chlorida $(\mathrm{Cl})$ mendapatkan nilai p-value $0,002(p<0,05)$ yang berarti kadar Chlorida sebelum dan sesudah perlakuan berbedasignifikanpadakelompokringerfundin. Dimana pada kelompok ringerfundin didapatkan nilai selisih penurunan rata-rata kadar Chlorida sebesar 3,50, sehingga dapat diketahui adanya penurunan kadar Chlorida sebesar 3,22\% (3,50/108,6*100\%).

Berdasarkan uraian diatas maka dapat diketahui bahwa terdapat perbedaan yang signifikan kadar elektrolit $(\mathrm{Na}, \mathrm{K}$, dan $\mathrm{Cl}$ ) sebelum dan sesudah perlakuan pada kelompok yang diberi cairan ringerfundin. Dimana terjadi penurunan kadar $\mathrm{Na}=2,0 \%$, $\mathrm{K}=12,1 \%$, dan $\mathrm{Cl}=3,2 \%$.

Tabel 6 Perbedaan Kadar Elektrolit (Na, K, Dan Cl) Sebelum dan Sesudah Perlakuan Pada kelompok Tetraspan

\begin{tabular}{cccc}
\hline Tetraspan & Sebelum & Sesudah & p-value \\
\hline $\mathrm{Na}$ & $139,60 \pm 3,57$ & $138,70+3,30$ & 0,134 \\
$\mathrm{~K}$ & $4,06 \pm 0,70$ & $4,01+0,77$ & 0,427 \\
$\mathrm{Cl}$ & $108,20 \pm 1,93$ & $108,10+2,38$ & 0,859 \\
\hline
\end{tabular}

Tidak terdapat perbedaan yang signifikan kadar elektrolit ( $\mathrm{Na}, \mathrm{K}$, dan $\mathrm{Cl}$ ) sebelum dan sesudah perlakuan pada kelompok yang diberi cairan tetraspan. Dimana terjadi penurunan kadar $\mathrm{Na}=0,64 \%, \mathrm{~K}=1,23 \%$, dan $\mathrm{Cl}=$ $0,09 \%$

Berdasarkan hasil penelitian maka dapat diketahui bahwa baik ringerfundin dan tetraspan sama-sama dapat mencegah turunnya elektrolit pada pasien operasi ( $\mathrm{p}>0,05)$. Akan tetapi pada kelompok ringerfundin terjadi penurunan/perubahan kadar elektrolit yang signifikan $(\mathrm{p}<0,05)$, sedangkan pada kelompok tetraspan kadar elektrolit tidak terjadi penurunan/perubahan signifikan $(p>0,05)$ sehingga dapat diketahui bahwa terdapat perbedaan pengaruh pemberian ringerfundin dan tetraspan terhadap perubahan kadar elektrolit.

\section{Pembahasan}

Manajemen terapi cairan pada perioperatif bertujuan untuk mempertahankan delivery oxygen. Terdapat beberapa pilihan terapi cairan yang tersedia. Pilihan terbaik pada prinsipnya dapat mempertahankan delivery oksigen yang dilihat dari hemodinamik yang stabil, perbaikan perfusi ke jaringan, mempertahankan keseimbangan elektrolit, dan asam basa tubuh.

Terapi cairan yang paling baik dan ideal untuk mengganti cairan akibat kehilangan darah adalah cairan yang mirip dengan cairan plasma dan darah yang hilang tersebut. Terapi cairan dengan Ringerfundin yang dipakai mengandung air, elektrolit, dan malat sebagai buffernya.

Penelitian ini menunjukan hasil bahwa jika kadar elektrolit dibandingkan antara ringerfindin dan tetraspan maka diketahui bahwa tidak ada perbedaan kadar elektrolit $(\mathrm{Na}, \mathrm{K}$, dan $\mathrm{Cl}$ ) antara kelompok ringerfindin dan tetraspan setelah adanya perlakuan. Sehingga dapat dikatakan bahwa baik cairan ringerfundin dan tetraspan dapat sama-sama dapat menjaga keseimbangan kadar elektrolit setelah adanya operasi. Akan tetapi jika di uji secara sendiri-sendiri diketahui bahwa pada kelompok ringerfundin terdapat perbedaan 
yang signifikan kadar elektrolit ( $\mathrm{Na}, \mathrm{K}$, dan $\mathrm{Cl}$ ) sebelum dan sesudah perlakuan dengan nilai $p$-value $<0,05$. Dimana terjadi penurunan kadar $\mathrm{Na}=2,0 \%, \mathrm{~K}=12,1 \%$, dan $\mathrm{Cl}=$ $3,2 \%$. Berbeda dengan kelompok tetraspan. Berdasarkan hasil penelitian diketahui bahwa tidak terdapat perbedaan yang signifikan kadar elektrolit ( $\mathrm{Na}, \mathrm{K}$, dan $\mathrm{Cl}$ ) sebelum dan sesudah perlakuan pada kelompok yang diberi cairan tetraspan dengan nilai $\mathrm{p}$-value $>0,05$. Dimana terjadi penurunan kadar $\mathrm{Na}=$ $0,64 \%, \mathrm{~K}=1,23 \%$, dan $\mathrm{Cl}=0,09 \%$. Hal ini menunjukkan bahwa tetraspan lebih baik dalam mempertahankan keseimbangan elektrolit (Natrium, Kalium, dan Chlorida) dibandingkan dengan ringerfundin.

Penelitian ini memberikan hasil bahwa pemberian tetraspan sebagai cairan perioperatif dapat mempertahankan keseimbangan kadar elektrolit tubuh lebih baik daripada cairan ringerfundin.

\section{KESIMPULAN}

Ringerfundin dan tetraspan sama-sama dapat menjaga keseimbangan elektrolit pada pasien operasi $(p>0,05)$. Akan tetapi pada kelompok ringerfundin terjadi penurunan/ perubahan kadar elektrolit yang signifikan $(\mathrm{p}<0,05)$, sedangkan pada kelompok tetraspan kadar elektrolit tidak terjadi penurunan/ perubahan signifikan $(p>0,05)$ sehingga dapat disimpulkan bahwa terdapat perbedaan pengaruh pemberian ringerfundin dan tetraspan terhadap perubahan kadar elektrolit. Dimana pemberian tetraspan sebagai cairan perioperatif dapat mempertahankan keseimbangan kadar elektrolit tubuh lebih baik daripada cairan ringerfundin.

\section{DAFTAR PUSTAKA}

Abdelrachman RS, Elzeftawy AE. 2007. Comparison of colloid versus crystalloid preload for prevention of hypotension during spinal anesthesia for elective section cesarean. Tanta Med Sciences J. 2007; 2(1):134-41.

Birnbach DJ, Browne IM. 2005. Anesthesia for obstetrics. Dalam: Miller RD. Miller's anesthesia. Edisi 6. Pennsylvania: Elsevier Churchill Livingstone. Pp: 326-29.

Darwis D, Moenajat Y, Nur B.M, Madjid A.S,Siregar P, Aniwidyaningsih W, dkk. 2008. Fisiologi Keseimbangan Air dan Elektrolit dalam Gangguan Keseimbangan Air-Elektrolit dan Asam-Basa, Fisiologi, Patofisiologi, Diagnosis dan Tatalaksana, ed. ke-2. Jakarta: FKUI. Pp: 29-114.

Eaton D.C. dan Pooler J.P. 2009. Vander's Renal Physiology, 7th Ed. Atlanta: McGraw Hill Companies Inc. pp: 77-154.

Fischbach F, Dunning M.B, Talaska F, Barnet M, Schweitzer T.A, Strandell C, et al. 2009. 'Chlorida, Potassium, Sodium' In: A Manual of Laboratory and Diagnostic Test, 8th Ed., Lippincot Wiliams and Wilkins. Pp: 997-1009.

Ganong W.F, 2005. Fungsi Ginjal dan Miksi pada Buku Ajar Fisiologi Kedokteran, edisi ke-22. Jakarta: Penerbit Buku Kedokteran EGC. Pp: 725-756.

Guyton A.C and Hall J.E. 2008. dalam: Buku Ajar Fisiologi Kedokteran Edisi ke-11. Jakarta: Penerbit Buku Kedokteran EGC. Pp: 307 - 400

Klutts J.S. and Scott M.G. 2006. 'Physiology and disorders of Water, Electrolyte, and AcidBase Metabolism' In: Tietz Text Book of Clinical Chemistry and Molecular Diagnostics, 4th Ed. Vol.1. Philadelphia: Elsevier Saunders Inc. pp: 1747-1775.

Lobo DL; Lewington, Andrew JP; Allison, Simon P. 2013. Basic Concept of Fluid and Electrolyte Therapy. Bibliomed - Medizinische Verlagsgesellschaft mbH, Melsungen 2013 
Lorenz, M. D., L. M. Cornelius, dan D. C. Ferguson. 1997. Small Animal Medical Therapeutics. Philadelphia: Lippincott Raven Publisher.

Matfin G. and Porth C.M. 2009. 'Disorders of Fluid and Electrolyte Balance' In: Pathophysiology Concepts of Altered Health States, $8^{\text {th }}$ Edition. USA: McGraw Hill Companies. pp. 761803.

Mulyono I, Harijanto E, Sunatrio S. 2009. Cairan koloid. Dalam: Panduan tata laksana terapi cairan perioperatif. Jakarta: Perhimpunan dokter spesialis anestesiologi dan reanimasi Indonesia. Pp: 130-31.

O'Callaghan C. 2009. 'Sains Dasar Ginjal dan Gangguan Fungsi Metabolik Ginjal' At a Glance Sistem Ginjal, Edisi Kedua, Jakarta: Penerbit Erlangga, pp: 22-68.

Prough DS, Funston JS., Svensen CH., Wolf SW. 2009. Fluid, Electrolytes, and Acid Base Physiology dalam Clinical Anesthesia $6^{\text {th }}$ Edition. USA: Lippincott Williams \& Wilkins

Reilly R.F and Perazella M.A. 2007. In: Lange Acid-Base Fluids and Electrolytes. USA: McGraw Hill Companies Inc. pp. 21-170.

Riley ET, Cohen SE, Rubenstein AJ, Flanagan B. 1995. Prevention of hypotension after spinal anesthesia for cesarean section: six percent hetastarch versus lactated ringer's solution. AnestAnalg. 1995; 81(4): 838-42

Sacher R.A. dan Mcpherson R.A. 2002. 'Pengaturan Asam-Basa dan Elektrolit' pada: Tinjauan Klinis Hasil Pemeriksaan Laboratorium, edisi kedua. Jakarta: Penerbit Buku Kedokteran EGC. Pp: 320-340.

Scott M.G., LeGrys, V.A. and Klutts J. 2006. 'Electrochemistry and Chemical Sensors and Electrolytes and Blood Gases" In: Tietz Text Book of Clinical Chemistry and Molecular Diagnostics, 4th Ed. Vol.1, Philadelphia: Elsevier Saunders Inc. pp: 93-1014.

Singer G.G and Brenner B.M. 2008. 'Fluid and Electrolyte Disturbances' In: Harrison's Principles of Internal Medicine, 17th Ed., Vol.1. USA: McGraw Hill Companies. pp. 274287.

Siregar P. 2009. 'Gangguan Keseimbangan Cairan dan Elektrolit' dalam: Buku Ajar Ilmu Penyakit Dalam, Edisi ke-5. Jakarta: Interna publishing. Pp: 175-189.

Stefan Silbernagl and Florian Lang. 2007. Teks dan Atlas Berwarna Patofisiologi, Jakarta: Penerbit Buku Kedokteran EGC. Pp: 92-125.

Suriyadi, Harahap Sofyan M, Ery Leksana. 2012. Pengaruh HES 6 \% Dalam Larutan Berimbang Dengan HES 6 \% Dalam Larutan Nacl 0,9 \% Terhadap pH, Strong Ion Difference Dan Klorida Pada Pasien Bedah Sesar Dengan Anestesi Spinal. Jurnal Anestesiologi Indonesia Volume IV, Nomor 1, Tahun 2012

Widmaier E.P, Raff H. dan Strang K.T. 2004. 'The Kidney and Regulation of Water and Inorganic Ions' In: Vander Human Physiology: The Mechanisms of Body Function, $9^{\text {th }}$ Edition, McGraw Hill Publishing. pp. 513-557.

Wilkes NJ, Woolf R, Mutch M, Mallett SV, Peachey T, Stephens R, Mythen MG. 2001. The Effect of balanced versus saline-based Hestastarch and crystalloid solution in acid-base and electrolyte status and gastric mucosal perfusion in elderly surgical patient. Anesth Analg. 2001 Oct;93(4):811-6. 